\title{
RANCANG BANGUN MESIN PENCAMPUR KEDELAI DENGAN KAPANG (RAGI TEMPE) PADA INDUSTRI RUMAHAN DI DAERAH KOTA MATARAM
}

\author{
Design and Construction of Soybean and Mold Mixing Tool on Home Industry at Mataram City \\ Surya Abdul Muttalib ${ }^{1, *)}$, Wiwin Apriyanditra ${ }^{2}$, Irma Yulianti², Rizki Hasmi², \\ M. Umas Hartono ${ }^{2}$ \\ ${ }^{1}$ Staf Pengajar Program Studi Teknik Pertanian Fakultas Teknologi Pangan dan Agroindustri \\ Universitas Mataram \\ ${ }^{2}$ Mahasiswa Program Studi Teknik Pertanian Fakultas Teknologi Pangan dan Agroindustri \\ Universitas Mataram \\ E-mail ${ }^{*}$ : suryaunram15@gmail.com
}

Diterima: 1 Februari 2017

Disetujui: 20 Februari 2017

\begin{abstract}
Kekalik Jaya has been famous as a center of tempe production in Mataram City. Generally, the production of tempe use traditional method. One important process in tempe production is the mold fermentation phase. The quality of tempe is defined based on color, density, and the distribution of mold on its surface. Therefore, the mold mixing phase needs to be optimized to maintain its quality; the producer needs to be introduced with simple technology of mixing tool. Beside the tempe productions, some people in Sandubaya Mataram work as iron craftsman. The effort on designing this mixing tool is expected to increase relations between these industries. This tool is designed using engine as a driving source to rotate the cylinder tube. The power is transmitted to the cylinder using vanbelt. The cylinder rotates on certain speed, equipped with inside fin to distort the tempe ingredients, to mixed them well in accordance with the cylinder rotation.
\end{abstract}

Keywords: mixing tool, construction, tempe

\begin{abstract}
ABSTRAK
Kekalik Jaya adalah salah satu sentra produksi bahan olahan berupa tempe di wilayah Mataram. Pada pengolahannya secara umum masih menggunakan metode tradisional.Proses pembuatan tempe yang memegang bagian penting penentu mutu tempe adalah proses peragian tempe dengan kapang.Kualitas tempe dinilai berdasarkan warna tempe, tingkat kepadatan tempe, sebaran kapang yang tumbuh menyelimuti tempe.Sehingga untuk menjaga nilai mutu tersebut, pencampuran ragi dengan kedelai perlu pengerjaan yang optimal guna menjaga kualitas tempe. Untuk tetap mempertahankan mutu tempe, para produsen perlu untuk diberikan pengenalan teknologi sederhana dalam proses produksi tempe berupa mesin pencampur. Selain usaha tempe, masyarakat Mataram juga menekuni usaha pengrajin besi, yang berada didaerah sandubaya Mataram. Dengan adanya desain alat ini dapat membantu para pengrajin semakin memiliki hubungan yang erat dengan pengusaha tempe sehingga perekonomian Mataram semakin meningkat antar sektor industrinya. Desain mesin ini menggunakan motor sebagai sumber penggerak, sehingga tabung silinder berputar. Tenaga dari motor ditransmisikan ke silinder oleh vanbelt. Silinder berputar dengan kecepatan tertentu, dengan sirip dalam yang mampu membolak-balikkan bahan hingga tercampur rata seiring dengan berputarnya silinder.
\end{abstract}

Kata kunci: mesin pencampur, rancang bangun, tempe 


\section{PENDAHULUAN}

Kota Mataram merupakan kota dengan banyak sekali potensi, salah satunya adalah potensi pada bidang industri, diantaranya usaha tahu, tempe dan pengrajin besi. Di Kota Mataram usaha tahu dan tempe berpusat di Kelurahan Kekalik. Berdasarkan keputusan Walikota Mataram nomor 526/X/2009 tentang penetapan klaster industri kecil unggulan Kota Mataram, Kelurahan Kekalik memiliki posisi ke-3 sebagai produsen tempe dan tahu, yakni sebanyak 227, dengan pengusaha tempe sebanyak 113, dengan kedelai untuk memproduksi tempe dan tahu mencapai 20 ton per hari dengan nilai investasi sekitar 10 juta rupiah (Keputusan Walikota Mataram Nomor 526/X/200 dalam Sushanti, 2015).

Umumnya industri tempe di Kelurahan Kekalik masih mengolah tempe secara tradisional. Proses pembuatan tempe yang memegang bagian penting penentu mutu tempe adalah proses pencampuran kedelai atau peragian tempe dengan kapang. Selama ini para pengrajin menggunakan sutil sebagai batang pengaduk, kedelai yang akan diragi diletakkan di atas terpal yang dibentangkan di atas lantai, pencampuran biasanya dilakukan oleh 2-3 orang. Jika proses peragian gagal maka proses pembuatan tempe akan menjadi gagal sehingga tempe yang dihasilkan akan rusak bahkan ragi tidak dapat tumbuh dengan baik membentuk tempe yang padat.

Selain usaha tahu dan tempe, usaha kerajinan logam menempati kelas ke-4, namun lokasi usaha kerajinan logam di wilayah Kota Mataram berpusat di wilayah Babakan (Sandubaya, Mataram). Secara dominan masyarakat Babakan memiliki bengkel besar yang didukung dengan prasarana kerja yang baik, yang didirikan bersamaan dengan lokasi pemukimannya. Dengan keadaan permasalahan teknologi di bidang industri tahu dan tempe dapat membantu untuk memberikan suatu potensi pengembangan industri logam Babakan untuk memproduksi suatu mesin yang memiliki teknologi sederhana untuk dapat diterapkan secara nyata di industri tahu dan tempe. Hal ini dapat membantu untuk meningkatkan pendapatan pada kedua sektor industri meskipun berbeda. Sehingga kedua industri akan saling membangun seiring dengan pertumbuhan teknologi yang sangat pesat (Keputusan Walikota Mataram Nomor 526/X/200 dalam Sushanti, 2015).

Rumusan masalah yang akan dipecahkan melalui penelitian ini, yaitu mendesain mesin pencampur kedelai dengan ragi tempe yang memiliki teknologi sederhana, untuk dapat diproduksi oleh pengerajin logam di wilayah Babakan (Sandubaya), dan diterapkan secara nyata di industri tempe wilayah Kekalik. Dengan demikian ditetapkan tujuan khusus dari penelitian ini, yaitu untuk:

1. Mendesain mesin pencampur kedelai dan ragi tempe yang sesuai dengan bahan baku tempe

2. Membuat mesin yang sesuai dengan standar mutu tempe

Tempe adalah salah satu hasil pangan dari Indonesia, yang dalam proses pembuatannya dengan cara fermentasi dari kacang kedelai atau kacang-kacang yang lainnya yang dapat difermentasikan dengan kapang Rhizopus oligosporus menjadi tempe. Perbandingan ragi atau kapang tempe ke dalam kedelai adalah sebanyak $2 \%$ dari berat kacang kedelainya. Tahap ini merupakan tahap penentu keberhasilan pembuatan tempe kedelai. Banyak sedikitnya sebaran kapang dipengaruhi oleh suhu dan keadaan udara di sekitar tempat pembuatan tempe. Semakin tinggi suhu udara sekitar maka semakin sedikit kapang yang tersebar begitu pula sebaliknya pada suhu rendah (Fauziah, 2013).

Pencampuran adalah suatu operasi yang menggabungkan dua macam atau lebih komponen bahan yang berbeda hingga tercapai suatu keseragaman. Tujuan dari pencampuran adalah bergabungnya bahan menjadi suatu campuran yang sedapat mungkin memiliki penyebaran yang sempurna atau sama. Salah satu alat yang digunakan untuk pencampuran adalah mixer (Indiyanto, 2013).

Merancang adalah suatu usaha untuk merencanakan, menggambar dan membuat suatu alat yang akan digunakan dalam kehidupan manusia. Rancang bangun alat dan mesin merupakan suatu usaha untuk menciptakan atau mengembangkan suatu peralatan yang digunakan untuk memudahkan pekerjaan manusia, dimulai dengan menemukan masalah dan menganalisisnya, kemudian merencanakan alat dan membuat bentuk sederhananya. Setelah dilakukan uji kinerja pada alat tersebut dilakukan proses 
evaluasi untuk perbaikan lebih lanjut (Harli M, 2004).

\section{METODE PENELITIAN}

\section{Alat danBahan}

Alat-alat yang digunakan dalam pelaksanaan penelitian ini diantaranya adalah:
1. Mesin bor
4. Meteran
2. Mata bor
5. Grinda
3. Palu
6. Mesin Las

Adapun bahan-bahan yang digunakan dalam pelaksanaan penelitian ini diantaranya adalah:
1. Plat stainles steel
14. Kabel
2. Besi siku $3 \times 3$
15. Stop kontak
3. Mur
16. Kapang
4. Baut
17. Kedelai
5. Kawat las
18. Plastik kemasan
6. Engsel
7. Cantelan
8. Motor 1,4 HP
9. Pulley $(7,4 \mathrm{~cm}, 28 \mathrm{~cm}$, $6,4 \mathrm{~cm}, 7 \mathrm{~cm}, 9 \mathrm{~cm})$
10. V-belt
11. Poros diameter $2 \mathrm{~cm}$
12. Bantalan
13. Amplas

\section{Tahapan Penelitian}

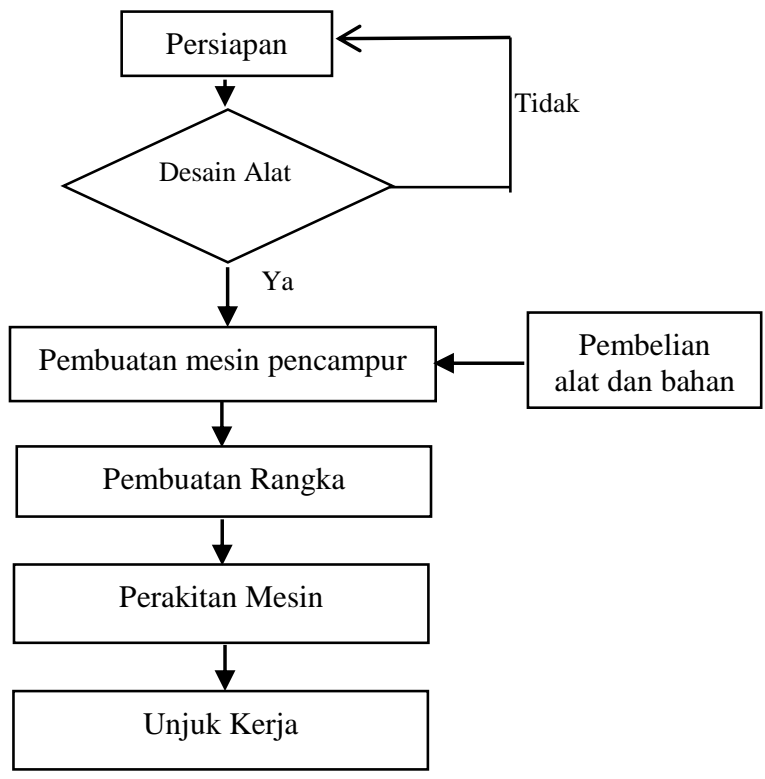

Gambar 1. Alur Penelitian
Parameter unjuk kerja Mesin Pencampur Ragi Tempe:

1. Kapasitas kerja

$\mathrm{C}=\frac{\mathrm{m}}{\mathrm{t}}$ dalam $(\mathrm{kg} / \mathrm{jam})$

Dimana:

$\mathrm{m}=\operatorname{massa}(\mathrm{Kg})$

$\mathrm{t}=$ waktu (jam)

2. Kecepatan Putar Ruang Pencampur (Rpm)

$\mathrm{Rpm}=\frac{\mathrm{n}_{1}}{\mathrm{n}_{2}}=\frac{\mathrm{D}_{2}}{\mathrm{D}_{1}}$

Dimana:

$\mathrm{n}_{1}=\mathrm{Rpm}$ Motor

$\mathrm{n}_{2}=$ Rpm Alat

$\mathrm{D}_{1}=$ Diameter Vulley Motor

$\mathrm{D}_{2}=$ Diameter Vulley Alat

\section{PEMBAHASAN}

Mesin yang akan dibuat memiliki dimensi yakni, diameter sebesar $40 \mathrm{~cm}$, tinggi selimut $54 \mathrm{~cm}$, tinggi kaki $95 \mathrm{~cm}$. Hal ini dilakukan untuk memberikan ruang pembalikan yang lebih luas sehingga pencampuran kedelai dengan kapang lebih merata. Bahan utama yang digunakan dalam membuat ruang pencampuran adalah stainless steel, dimana stainless steel merupakan salah satu baja tahan karat meski telah tergores sekalipun atau bahkan dicuci dengan air.

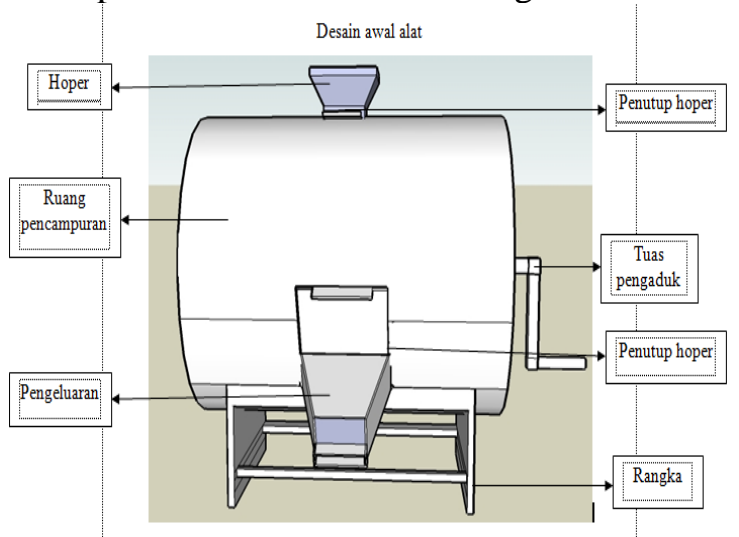

Gambar 2. Rancangan Awal Mesin Pencampur

Dilakukan pengkajian ulang secara seksama sebelum diputuskannya bentuk akhir rancangan mesin. Rancangan mesin awalnya (Gambar 1), pada bagian dalam mesin, yakni ruang pencampur dibentuk sirip pada bagian poros tengah sebagai batang pengaduk bahan. Karakteristik yang dimiliki kedelai saat diolah adalah kedelai semi basah yang terlebih dahulu direbus kemudian dianginkan. Agar bahan tidak rusak saat diolah, maka pada bagian 
dalam mesin sirip diletakkan pada permukaan selimut bagian dalam sebanyak tiga sirip, ini ditujukan agar saat proses pembalikan dan pencampuran tidak akan merusak bahan, dan bahan akan terbalik secara sempurna di dalam ruang pencampur.

Pada bagian ruang pemasukan bahan, bentuk desain awal hopper berbentuk kerucut. Namun setelah dikaji, jika bentuk hopper kerucut operator akan kesulitan saat memasukkan bahan dalam jumlah banyak dan sulit menaburkan kapang agar lebih merata pada bahan, sehingga diputuskan hopper dibentuk langsung dengan melubangi ruang pencampur secara memanjang dan ditutup dengan bentuk yang sama, agar bahan dapat dipastikan tidak keluar berserakan saat dilakukan proses pencampuran. Pada bagian pengeluaran, awalnya berbentuk kerucut dengan ukuran yang lebih kecil. Namun, dengan memperhatikan aspek tersebut diputuskan lubang pemasukan difungsikan pula sebagai lubang pengeluaran bahan dan pada bagian bawah mesin dilengkapi dengan alas agar bahan tidak jatuh tercecer di lantai maka bentuk alas bagian bawah dibentuk miring pada bagian depan agar bahan langsung terjatuh pada bak penampung.

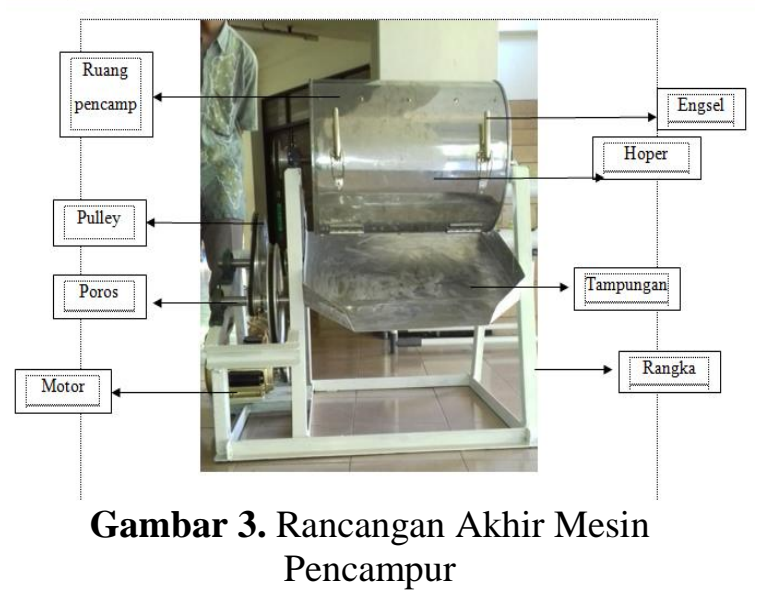

Rancangan mesin (Gambar 2) diterima dengan baik oleh pihat mitra, sehingga pihak mitra bersedia untuk membuat mesin (Gambar 3) yang telah dirancang dengan bantuan anggaran dari dana hibah. Rancangan ini sangat membantu dalam proses keberlangsungan produksi mitra, karena mitra biasanya hanya bekerja atau memproduksi alatalat pertanian, yang biasa digunakan dalam proses penanganan pasca panen hasil pertanian dan mesin-mesin penunjang dalam pertanian.
Hasil unjuk kerja rata-rata mesin Pencampur Ragi Tempe dapat dilihat pada Tabel 1.

Tabel 1. Hasil unjuk kerja mesin pencampur ragi tempe

\begin{tabular}{clcl}
\hline No & Parameter & $\begin{array}{c}\text { Nilai } \\
\text { rata-rata }\end{array}$ & Satuan \\
\hline 1 & Kapasitas Kerja & 85,47 & $\mathrm{Kg} / \mathrm{jam}$ \\
2 & Kecepatan & 370 & $\mathrm{rpm}$ \\
& $\begin{array}{l}\text { Putaran Ruang } \\
\text { Pencampur }\end{array}$ & & \\
\hline
\end{tabular}

Berdasarkan hasil unjuk kerja mesin diharapkan dapat membantu mitra dalam menaikkan nilai produksi dan bersaing dalam peningkatan ekonomi, karena rancangan mesin ini dapat dipasarkan oleh pihak mitra secara langsung pada pengrajin tempe. Rancangan ini membantu pihak mitra terus menumbuhkan hubungan baik antar industri dan membantu menumbuhkan perekonomian wilayah Mataram, khususnya untuk para pengrajin tempe dan para pengrajin besi.

\section{KESIMPULAN \& SARAN}

\section{Kesimpulan}

Berdasarkan pelaksanaan dan
pembahasan yang telah dipaparkan sebelumnya, dapat ditarik kesimpulan sebagai berikut:

1. Pembuatan mesin dilakukan dengan mendesain model mesin, memilih bahan yang tepat dan memproduksi mesin dalam skala laboraturium.

2. Tahapan pembuatan mesin dilaksanakan dari persiapan alat dan bahan penyusun mesin, pembuatan tabung pencampur, pembuatan krangka mesin, perakitan mesin, dan pemasangan daya.

3. Mesin dibuat dengan dimensi selimut berdiameter $40 \mathrm{~cm}$ dan tinggi $54 \mathrm{~cm}$. Mesin dibuat dari bahan stainless steel.

\section{Saran}

Perlu adanya penelitian lebih lanjut mengenai mesin ini, untuk dapat diterapkan di industri kecil yang ada di masyarakat, dengan mempertimbangkan standar mutu tempe. 
DAFTAR PUSTAKA

Fauziah. 2013. Kajian Reka Bentuk Pembungkusan Produk Tempe.

Universitas Malaysia. Sarawak.

Harli, M. 2004. Intisari Perbengkelan. PT. Gramedia. Jakarta

Indiyanto, Rus. 2013. Diktat Pengantar Pengetahuan Bahan Teknik. Universitas Pembangunan Nasional "Veteran". Surabaya.

Sushanti, Ima. 2015. Pengaruh Keberadaan Industri Terhadap Perumahan dan Kawasan Permukiman di Kota Mataram. Jurnal Sosial Ekonomi dan Humaniora 1 (1). 